Behavioural pharmacology

\title{
Role of Hypothalamic-Pituitary-Adrenal axis and corticotropin-releasing factor stress system on cue-induced relapse to alcohol seeking
}

\author{
Fernanda L. Galesi ${ }^{\text {a }}$, Lydia O. Ayanwuyi ${ }^{\text {b }}$, Miriam Garcia Mijares ${ }^{\text {a }}$, Andrea Cippitelli ${ }^{\text {b }}$, \\ Nazzareno Cannella $^{\mathrm{b}}$, Roberto Ciccocioppo ${ }^{\mathrm{b}}$, Massimo Ubaldi ${ }^{\mathrm{b}, *}$ \\ a Universidade de São Paulo, Instituto de Psicologia, Departamento de Psicologia Experimental, Sao Paulo, SP, Brazil \\ ${ }^{\mathrm{b}}$ School of Pharmacy, Pharmacology Unit, University of Camerino, Camerino, MC 62032, Italy
}

\section{A R T I C L E I N F O}

\section{Article history:}

Received 25 November 2015

Received in revised form

26 May 2016

Accepted 13 June 2016

Available online 15 June 2016

Keywords:

Alcohol

Relapse

Stress

CRF

Addiction

Reinstatement

\begin{abstract}
A B S T R A C T
A large body of evidence has shown that the Corticotropin Releasing Factor (CRF) system, which plays a key role in stress modulation, is deeply involved in relapse to alcohol seeking induced by exposure to stressful events such as foot shock or yohimbine injections. Exposure to environmental cues is also known to be a trigger for alcohol relapse, nevertheless, the relationship between the relapse evoked by the cue-induced model and the CRF stress systems remains unclear.

The purpose of this study was to evaluate, in male Wistar rats, the involvement of the CRF system and Hypothalamic-Pituitary-Adrenal (HPA) axis in relapse induced by environmental cues. Antalarmin, a selective CRF1 receptor antagonist, Metyrapone, a corticosterone (CORT) synthesis inhibitor and CORT were evaluated for their effects on the reinstatement test in a cue-induced relapse model.

Antalarmin $(20 \mathrm{mg} / \mathrm{kg})$ blocked relapse to alcohol seeking induced by environmental cues. Metyrapone (50 and $100 \mathrm{mg} / \mathrm{kg}$ ) also blocked relapse in Wistar rats but only at the highest dose $(100 \mathrm{mg} / \mathrm{kg})$. Corticosterone had no effect on relapse at the doses tested.

The results obtained from this study suggest that the CRF stress system and the HPA axis are involved in cue-induced alcohol relapse.
\end{abstract}

(c) 2016 Elsevier B.V. All rights reserved.

\section{Introduction}

Alcoholism is a chronic relapsing disorder characterized by compulsive alcohol intake and a loss of control over alcohol consumption (Koob and Kreek, 2007; Koob, 2003; Koob et al., 2004).

During early stages of addiction the mesolimbic dopamine system plays a key role in mediating alcohol reward. Following chronic exposure to alcohol disregulation of the corticotropin releasing factor (CRF) system progressively occurs contributing to transition to later stages of addiction and relapse vulnerability (Koob and Kreek, 2007; Koob, 2003; Koob et al., 2004).

CRF is a 41-amino-acid neuropeptide that is the main modulator of the HPA axis. CRF is widely distributed in the brain with the higher expression in the paraventricular nucleus of the hypothalamus but is also present in extrahypothalamic areas (Vale

\footnotetext{
* Correspondence to: University of Camerino, School of Pharmacy, Pharmacology Unit, Building of Experimental Medicine, Via Madonna delle Carceri 9, Camerino, MC 62032, Italy.

E-mail address: massimo.ubaldi@unicam.it (M. Ubaldi).
}

et al., 1981). CRF binds preferentially to CRF1 receptors that are expressed in many brain areas, including amygdala, hippocampus, cortex and thalamus, and disregulation of this system has been linked to expression of negative affect and mood disorders such as anxiety and depression (Van Pett et al., 2000; Koob and Zorrilla, 2010, 2012; Zorrilla and Koob, 2004). At neuroendocrine level activation of CRF1R in the hypothalamus is the main mechanism responsible for activation of the HPA axis and subsequent stimulation of glucocorticoid synthesis and release (Smith and Vale, 2006).

Notably, glucocorticoids can interact with the dopaminergic system in the nucleus accumbens (NAcc) to give incentive value to drugs, which can lead to increased drug consumption in early stages of addiction (Deroche et al., 1997, 1993; Piazza et al., 1993). Consistently CORT administration has been found to increase alcohol self-administration (Fahlke et al., 1994a,b, 1995). Whereas, metyrapone, a corticosterone (CORT) synthesis inhibitor, decreases alcohol consumption in rats genetically selected for alcohol preference (Fahlke et al., 1994b). Additionally, chronic alcohol consumption, chronic stress and withdrawal have been reported 
to attenuate HPA axis activity (Koob and Kreek, 2007; Kreek and Koob, 1998; Rivier et al., 1990; Zorrilla et al., 2001).

With the shift from positive to negative reinforcement, extrahypothalamic systems gain additional relevance in alcohol addiction further contributing to promote drinking (Koob and Kreek, 2007; Koob, 2003; Koob et al., 2004). Consistent with this gain of function injections of CRF1 receptor antagonists in the central nucleus of the amygdala have been shown to reduce anxiety-like behaviors, motivational deficits by other reinforcers and the excessive drug self-administration initiated after acute abstinence (Heilig et al., 2010; Heilig and Koob, 2007; Koob and Zorrilla, 2010; Logrip et al., 2011).

Recent studies have shown that alcohol relapse is also highly connected with the CRF stress system as demonstrated by experiments showing that CRF receptor antagonists such as antalarmin (Cippitelli et al., 2012; Marinelli et al., 2007), D-Phe-CRF (Le et al., 2000) and CP-154526 (Le et al., 2000; Moffett and Goeders, 2007) can block stress-induced relapse to alcohol seeking.

In addition to stress, other factors are associated with drug seeking resumption following abstinence. One of such factors is the exposure to environmental cues associated with drug use (Bachteler et al., 2005; Cannella et al., 2009; Ciccocioppo et al., 2001, 2004, 2003; Stopponi et al., 2011; Vengeliene et al., 2007). Although it is well demonstrated that exposure to environmental cues can lead to relapse and that the CRF system is involved in relapse to alcohol use, the relationship between relapse induced by environmental cues and the CRF system has not been sufficiently studied yet.

Although previous findings (Liu and Weiss, 2002) seem to show that the CRF system is not involved in cue-induced relapse, the role of the CRF system in alcohol addiction is well established and its role in modulating withdrawal and behavioral responses associated with abstinence have been documented (Breese et al., 2011; Koob, 2010). Notably, in operant paradigms, responses occurring during extinction reinstatement tests (i.e. alcohol is not delivered as a consequence for responding) are associated with an increase in plasma CORT concentrations (Coover et al., 1971; Kawasaki and Iwasaki, 1997) implying that, when no longer reinforced, alcohol-related lever pressing may represent a stressful condition.

This work is aimed at investigating whether the CRF stress system and the HPA axis, due to these mechanisms, may contribute to relapse triggered by presentiation of cues previously associated with alcohol availability. To explore this hypothesis, animals were trained in the cue-induced relapse model and were injected intraperitoneally (i.p.) with the selective CRF1R receptor antagonist antalarmin, metyrapone and CORT before the reinstatement test.

\section{Materials and methods}

\subsection{Animals}

Male Wistar rats $(n=30)$ were purchased from Charles River (Calco, Lecco, Italy) and were 48 days old at the beginning of all the experiments. They were housed in pairs in a room on a reverse 12:12 h light/dark cycle (lights off at 8:00 a.m.), at a constant temperature of $20-22{ }^{\circ} \mathrm{C}$ and relative humidity of $45-55 \%$. The rats had free access to food and water except when otherwise stated. All the procedures were conducted in adherence to the European Community Council Directive for Care and Use of Laboratory Animals and the National Institutes of Health Guide for the Care and Use of Laboratory Animals.

\subsection{Drugs}

Ethanol solutions ( $10 \% \mathrm{v} / \mathrm{v})$ were prepared by diluting $95 \%$ alcohol (F.L. Carsetti s.n.c., Camerino, Italy) in tap water. The selective CRF1 receptor antagonist, antalarmin was obtained from National Institute on Alcohol Abuse and Alcoholism (NIAAA/NIH). As previously described (Cippitelli et al., 2012), antalarmin was suspended in a vehicle composed of $10 \%$ Tween 80 and distilled water. It was administered intraperitoneally (i.p.) at the doses of $10 \mathrm{mg} / \mathrm{kg}$ and $20 \mathrm{mg} / \mathrm{kg}$ in a volume of $1 \mathrm{ml} / \mathrm{kg}$. This dosage was based on our previous work on the effect of antalarmin on alcohol consumption in Wistar rats (Cippitelli et al., 2012). The CORT synthesis inhibitor metyrapone (Sigma-Aldrich) was dissolved in $40 \%$ propylene glycol and then diluted in physiological saline. It was administered i.p. at doses of $50 \mathrm{mg} / \mathrm{kg}$ and $100 \mathrm{mg} / \mathrm{kg}$ in a volume of $2 \mathrm{ml} / \mathrm{kg}$. The doses of metyrapone were based on a previous work that investigated the effect of metyrapone on relapse to cocaine seeking (Piazza et al., 1994). The glucocorticoid, CORT (Sigma-Aldrich) was dissolved in $1 \%$ Tween 80 , then diluted in distilled water and sonicated. It was administered i.p. at doses of $2.5 \mathrm{mg} / \mathrm{kg}$ and $5 \mathrm{mg} / \mathrm{kg}$ in a volume of $1 \mathrm{ml} / \mathrm{kg}$. Doses were chosen on the basis of previous studies (Brooks et al., 2004; Graf et al., 2013).

\subsection{Apparatus}

During the Alcohol Self-administration phase, volumetric drinking tubes ( $400 \mathrm{ml}$ capacity) were used to monitor liquids consumption. Training, extinction and reinstatement sessions were conducted in standard operant conditioning chambers (Med Associates ${ }^{\mathrm{TM}}$ ) placed inside sound attenuating boxes with an exhauster that provided air circulation. Each chamber was equipped with a drinking reservoir (volume capacity $0.30 \mathrm{ml}$ ) positioned $4 \mathrm{~cm}$ above the grid floor in the center of the front panel of the chamber. Two retractable levers were located $3 \mathrm{~cm}$ to the right or to the left of the drinking receptacle. An infusion pump was activated only by responses on the right (active) lever, while responses on the left (inactive) lever were recorded but did not result in the activation of the pump. Auditory and visual stimuli were presented via a speaker and a light located on the front panel. The floor was a stainless steel grid, under which a tray was always filled with wood shavings (bedding). A microcomputer with software and interface manufactured by Med Associates ${ }^{\mathrm{TM}}$ controlled the operation of the boxes and the recording of the behavioral data. To produce the olfactory (odor) stimuli used in training and reinstatement sessions, five drops (approximately $0.1 \mathrm{ml}$ ) of orange or anise extract were placed in the bedding before the beginning of sessions.

\subsection{Procedure}

\subsubsection{Alcohol self-administration training}

The purpose of this phase was to facilitate the development of voluntary alcohol self-administration in the animals. To achieve this objective, the animals received a solution containing $10 \%$ ethanol (10E) in their home cages for seven days and had free access to this solution $23.5 \mathrm{~h} /$ day. Alcohol consumption was measured every day.

\subsubsection{Shaping phase}

After the alcohol self-administration training phase, the animals were trained to press the right lever under a fixed ratio 1 (FR1) schedule of reinforcement. On the first day, they were placed into the operant boxes for $13 \mathrm{~h}$ and each lever pressing response resulted in the delivery of $0.1 \mathrm{ml}$ of water. In this session, food was placed above the tray. After the session, the animals were removed 
from the boxes and left for $24 \mathrm{~h}$ in their home-cages. The second session was the same as described above, but had $2 \mathrm{~h}$ length period and no food was given during the session. The third session was exactly the same as the second but was just of $1 \mathrm{~h}$ duration. The fourth session was of 30 min duration and each lever pressing response resulted in the delivery of $0.1 \mathrm{ml}$ of $10 \mathrm{E}$ instead of water. In these sessions both levers were available, but only responses at the right lever activated alcohol delivery while the left lever was used as control bar. The animals were not deprived of food or water during this phase.

\subsubsection{Conditioning phase}

Rats were trained to discriminate between $10 \%$ alcohol and water as previously described (Cannella et al., 2009) in order to discriminate the availability of alcohol (reward) vs water (nonreward). Conditioning sessions consisted of 20 randomly distributed 30-min daily sessions (10 for alcohol and 10 for water), during which discriminative stimuli (DS) predictive of alcohol vs water availability were presented. The DS for alcohol consisted of the odor of an orange extract $(S+)$, whereas water availability was signaled by an anise extract $(\mathrm{S}-)$. The olfactory stimuli were produced by depositing five to six drops of the respective extract into the bedding of the operant chamber immediately before extension of the levers and session initiation, and remained present throughout the 30-min sessions. In addition, each lever press resulting in delivery of alcohol was paired with illumination of the chamber's house light for $5 \mathrm{~s}$, while lever presses resulting in water delivery were followed by a 5-s white noise. Concurrently with the presentation of these stimuli, a 5-s time-out (TO) period was in effect, during which responses were recorded, but not reinforced by alcohol or water.

\subsubsection{Extinction phase}

The rats were the subjected to daily 30 -min extinction sessions for 10 consecutive days. During this phase, sessions began with the extension of the levers without the presentation of conditioned stimuli (presented during the conditioning phase) and the solutions self-administered, during the training phase. Responses at the previously active lever activated the syringe pump (delivery mechanism) but had no scheduled consequences.

\subsection{Experiment 1: effect of antalarmin on cue-induced reinstate- ment of alcohol seeking in Wistars rats}

On the day after the last extinction session Wistars rats $(n=10)$ were subjected to the reinstatement test. This test lasted for 30 min under conditions identical to those during the conditioning phase, except that alcohol and water were not available. On day 1 (first session), all animals were treated i.p. with the drug vehicle and presented with S-. Drug testing under S+ condition began on day 2 . Thus the second, third and fourth reinstatement sessions were employed to evaluate whether antalarmin was able to block the cue-induced reinstatement to alcohol seeking. Rats were treated i.p. with antalarmin (10 and $20 \mathrm{mg} / \mathrm{kg}$ ) or its vehicle $30 \mathrm{~min}$ before the reinstatement test according to a counterbalanced Latin square (within subject) design. A 3-day interval, during which animals remained in their home cage, was allowed between drug tests.

\subsection{Experiment 2: effect of metyrapone on cue-induced reinstate-} ment of alcohol seeking in Wistars rats

The procedure followed here was similar to the one used in Exp.1, the only difference was that metyrapone was used instead of antalarmin. In this experiment Wistar rats $(n=10)$ were treated i.p. with metyrapone (50 and $100 \mathrm{mg} / \mathrm{kg}$ ) or its vehicle $1 \mathrm{~h}$ before the reinstatement test according to a counterbalanced Latin square (within subject) design.

\subsection{Experiment 3: effect of CORT on cue-induced reinstatement of alcohol seeking in Wistars rats}

Using the same procedure described in Exp. 1 in this experiment the effect of CORT on cue-induced reinstatement of drug seeking was evaluated. For this purpose Wistars rats $(n=10)$ were treated i.p. with CORT (2.5 and $5 \mathrm{mg} / \mathrm{kg}$ ) or its vehicle $30 \mathrm{~min}$ before the reinstatement test according to a counterbalanced Latin square (within subject) design.

\subsection{Statistical analysis}

Performance during conditioning phase was analyzed by repeated measures ANOVA using 'reinforcer' (ethanol or water) as within subject factor. Reinstatement in the vehicle group was analyzed by repeated measures ANOVA using 'condition' (extinction, $S+$ or $S-$ ) as within subject factor. The effect of drug treatment was also analyzed by repeated measures ANOVA using 'drug dose' (vehicle, dose 1 , dose 2 ) as within subject factor. To control for nonspecific effects, the same statistical approach was used to evaluate inactive lever presses.

For all experiments analysis of variance was followed by the Bonferroni post hoc test when appropriate and statistical significance was set at $\mathrm{P}<0.05$.

\section{Results}

\subsection{Effect of antalarmin on cue-induced reinstatement of alcohol seeking in Wistars rats}

During the conditioning phase, Wistar rats learned to discriminate between alcohol and water-paired conditions. At the end of this phase, active lever pressing was significantly higher for alcohol than for water: $[F(1,9)=11.40, P<0.01]$. During the 10 extinction days, lever pressing at the previously alcohol and waterpaired lever progressively decreased.

In the reinstatement tests (Fig. 1), repeated measures ANOVA revealed that cues had a significant overall effect on alcohol seeking: $[\mathrm{F}(2,9)=11.46, \mathrm{P}<0.001]$. The post-hoc test showed a robust reinstatement of responding under $\mathrm{S}+$ presentation $(\mathrm{P}<0.001)$ but not under $\mathrm{S}-$ presentation $(\mathrm{p}>0.05, \mathrm{NS})$ compared to the mean response the of last three extinction days. Also, the mean response obtained during $\mathrm{S}+$ presentation was significantly higher than responses obtained in the presence of $\mathrm{S}-$ $(\mathrm{P}<0.001)$. As shown in Fig. 1 , pre-treatment with antalarmin significant reduced reinstatement to alcohol seeking. Repeated measures ANOVA showed an overall effect of treatment on responses: $[F(2,9)=31.02 ; \mathrm{P}<0.001]$. Post hoc analysis revealed that antalarmin at the dose of $20 \mathrm{mg} / \mathrm{kg}$ significantly reduced $(\mathrm{P}<0.001)$ alcohol seeking responses. No effect was detected at the lower dose. Responses on the inactive lever were almost absent throughout all experimental phases and were not modified by antalarmin treatment.

\subsection{Effect of metyrapone on cue-induced reinstatement of alcohol seeking in Wistars rats}

Repeated measures ANOVA showed that during the conditioning phase, Wistars rats learned to discriminate between alcohol and water-paired conditions, responding significantly more for alcohol than for water at the end of this phase: $[F(1,9)=30.95$, $\mathrm{P}<0.001$ ]. During the extinction phase, lever pressing at 


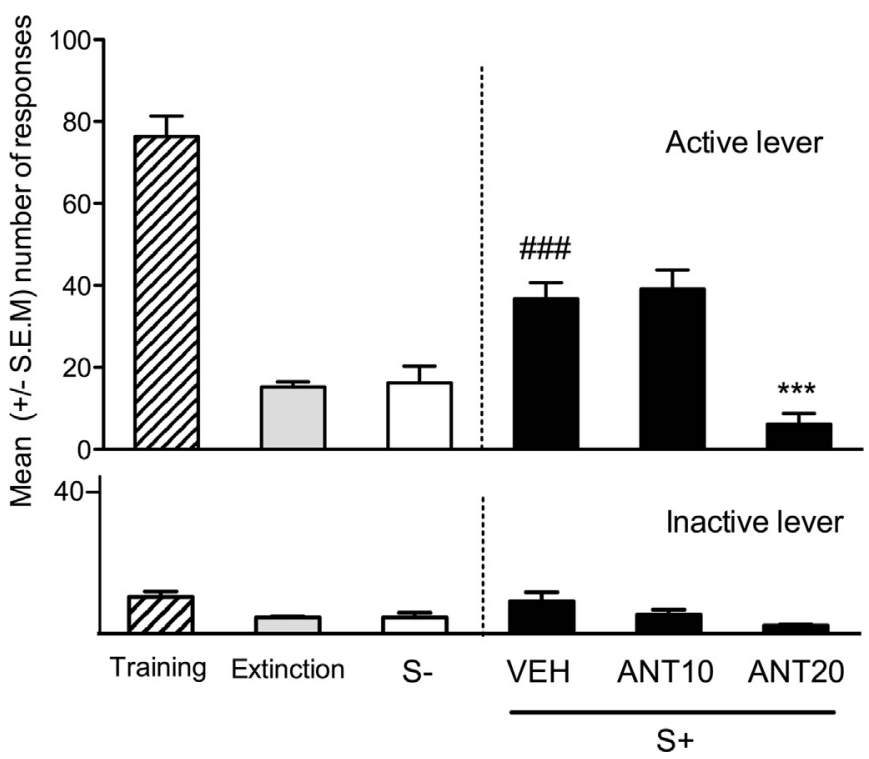

Fig. 1. Effect of Antalarmin on cue-induced reinstatement of alcohol-seeking behavior in Wistar $(n=10)$ rats. Data are mean ( \pm S.E.M.) number of responses on the active lever. TRAINING shows ethanol-reinforced responses at the end of training phase and EXTINCTION shows responses during the final three extinction sessions. During reinstatement sessions, animals were exposed to stimuli previously associated to alcohol availability $(\mathrm{S}+)$. When vehicle $(\mathrm{VEH})$ was administered, lever pressing responses increased compared to EXTINCTION and stimuli previously associated to water availability ( $\mathrm{S}-$ ). Administration of Antalarmin $20 \mathrm{mg} / \mathrm{kg}$ (ANT 20) blocked reinstatement while the dose of $10 \mathrm{mg} / \mathrm{kg}$ (ANT 10) had no effect.

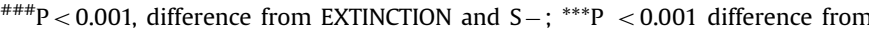
vehicle.

previously alcohol and water-paired lever progressively decreased.

In the reinstatement test (Fig. 2), repeated measures ANOVA revealed that cues had a significant overall effect on alcohol seeking $[\mathrm{F}(2,9)=13.84, \mathrm{P}<0.001]$. Further analysis with the post

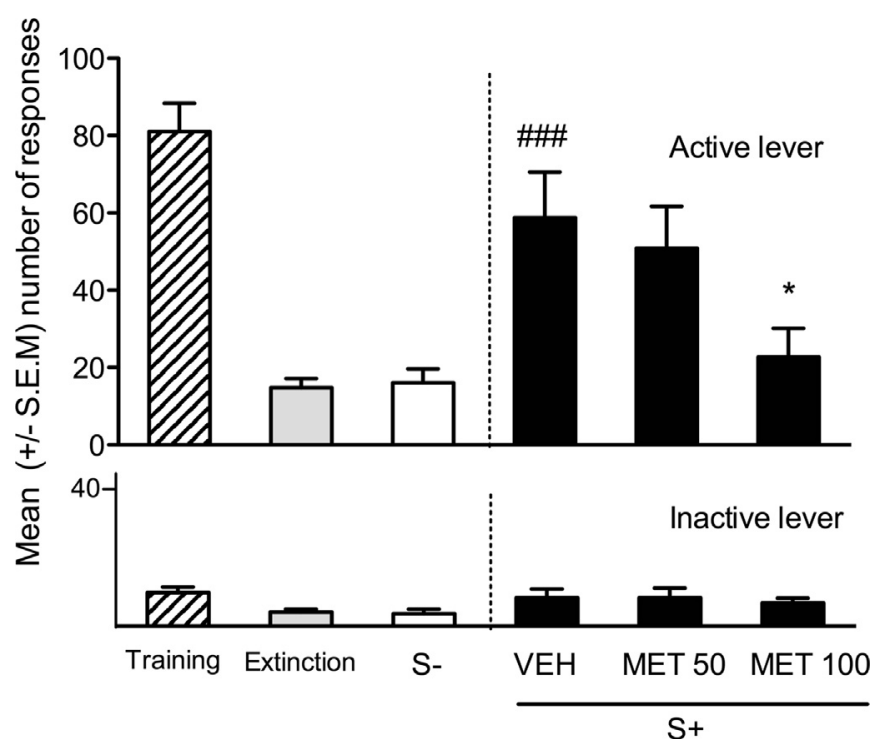

Fig. 2. Effect of Metyrapone on cue-induced reinstatement of alcohol-seeking behavior in Wistar $(n=10)$ rats. Data are mean $( \pm$ S.E.M.) number of responses on the active lever. TRAINING shows ethanol-reinforced responses at the end of training phase and EXTINCTION shows responses during the final three extinction sessions. During reinstatement sessions, animals were exposed to stimuli previously associated to alcohol availability $(\mathrm{S}+)$. When vehicle $(\mathrm{VEH})$ was administered, lever pressing responses increased compared to EXTINCTION and stimuli previously associated to water availability (S - ). Administration of Metyrapone $100 \mathrm{mg} / \mathrm{kg}$ (MET 100 ) blocked reinstatement while the dose of $50 \mathrm{mg} / \mathrm{kg}$ (MET 50) had no effect.

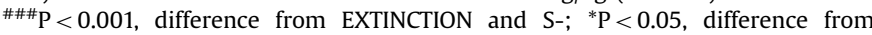
vehicle. hoc test showed a robust reinstatement of responding under $\mathrm{S}+$ presentation $(\mathrm{P}<0.001)$ but not under the $\mathrm{S}-$ presentation ( $p>0.05$, NS) compared to the mean response of the last three extinction days. Also, the mean lever response obtained during $\mathrm{S}+$ presentation was significantly higher than that obtained in during $\mathrm{S}-$ presentation $(\mathrm{P}<0.001)$.

Metyrapone administration elicited an overall significant effect on reinstatement $[\mathrm{F}(2,9)=4.22 ; \mathrm{P}<0.05]$. As shown in Fig. 2, post hoc analysis revealed that metyrapone at the highest dose $(100 \mathrm{mg} / \mathrm{kg})$ significantly reduced reinstatement to alcohol seeking $(\mathrm{P}<0.05)$. No effect was detected a the lower dose $(50 \mathrm{mg} / \mathrm{kg})$. Responses on the inactive lever were almost absent throughout all experimental phases and were not modified by metyrapone treatment.

\subsection{Effect of CORT on cue-induced reinstatement of alcohol seeking in Wistars rats}

During the conditioning phase, the animals learned to discriminate between alcohol and water-paired conditions. ANOVA showed that at the end of the training phase the animals were responding more for alcohol than for water $[F(1,18)=36.37$, $\mathrm{P}<0.001]$.

Upon analysis of the data obtained from the reinstatement test, ANOVA showed that the presentation of cues had a significant overall effect on alcohol seeking $[\mathrm{F}(2,36)=39.67, \mathrm{P}<0.001]$. The post hoc test indicated a higher responding under $\mathrm{S}+$ condition but not under the $\mathrm{S}$ - condition compared to the mean response of the last three extinction days $(\mathrm{P}<0.001)$ as well as $\mathrm{S}-$ condition $(\mathrm{P}<0.001)$. No effect of CORT administration on reinstatement was observed (Fig. 3). Responses on the inactive lever were almost absent throughout all experimental phases and were not modified by CORT treatment.

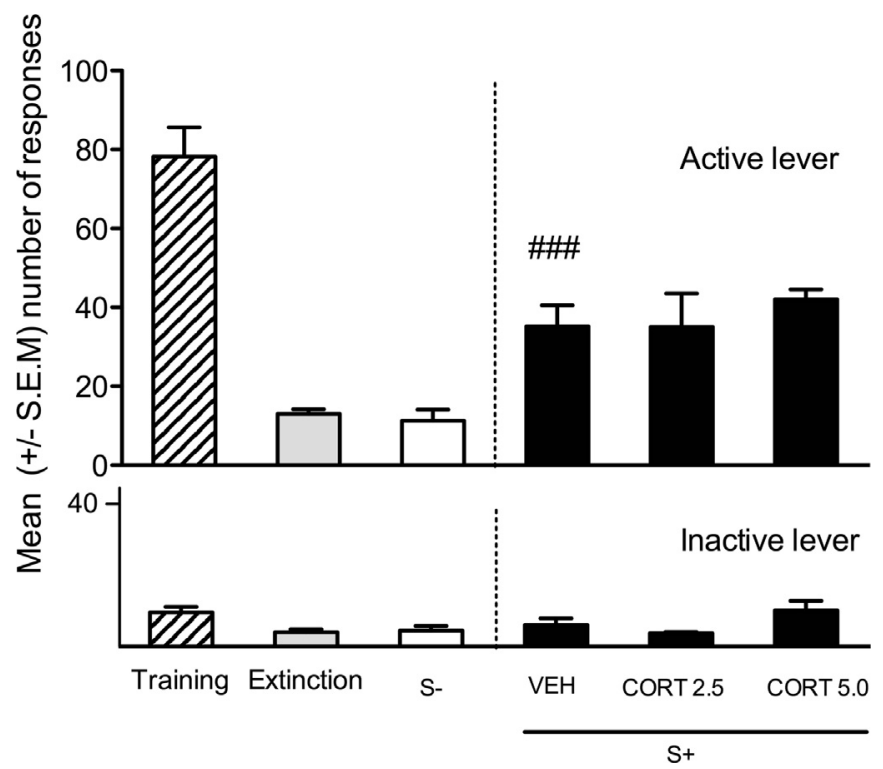

Fig. 3. Effect of corticosterone on cue-induced reinstatement of alcohol-seeking behavior in Wistar $(n=10)$ rats. Data are mean ( \pm S.E.M.) number of responses on the active lever. TRAINING shows ethanol-reinforced responses at the end of training phase and EXTINCTION shows responses during the final three extinction sessions. During reinstatement sessions, animals were exposed to stimuli previous associated to alcohol availability $(\mathrm{S}+)$. When vehicle $(\mathrm{VEH})$ was administered, lever pressing responses increased compared to EXTINCTION and with stimuli previously associated to water $(\mathrm{S}-)$. Corticosterone (CORT) administration had no effect on reinstatement at both doses tested. ${ }^{\# \# \# P}<0.001$, difference from EXTINCTION and $\mathrm{S}-$. 


\section{Discussion}

The purpose of this work was to evaluate the role of the CRF stress system and the HPA axis in cue-induced reinstatement to alcohol use in Wistar rats. Our results showed that pre-treatment with the CRF1 receptor antagonist antalarmin $(20 \mathrm{mg} / \mathrm{kg})$ blocked resumption of lever pressing suggesting that the CRF1 receptor is involved in the reinstatement to alcohol seeking in the cue-induced relapse model.

Previous studies have demonstrated that CRF1 receptor is implicated in relapse to alcohol seeking precipitated by stressful stimuli as shown by the fact that blockade of the CRF1 receptor prevents stress-induced relapse to drug seeking (Cippitelli et al., 2012; Le et al., 2000; Marinelli et al., 2007; Moffett and Goeders, 2007). Noteworthy, evidence have been provided indicating that this effect occurs through modulation of extrahypothalamic CRF pathways (Marinelli et al., 2007). Conversely, our findings suggest that when relapse is elicited by environmental conditioning factors ethanol seeking is associated with recruitment of hypothalamic CRF mechanisms involved in the regulation of the HPA axis. This can be inferred from data showing that pre-treatment with CORT synthesis inhibitor metyrapone prevented the expression of drug seeking in Wistars exposed to cues previously paired with alcohol availability,. Other studies also support our findings since it has been shown that ketoconazole, another corticosterone synthesis inhibitor and CP 154526, a selective CRF1 receptor antagonist, blocked relapse to cocaine seeking evoked by contextual stimuli predictive of drug availability (Goeders and Clampitt, 2002). In another study it was also observed that CP 154526 blocked cueinduced reinstatement of methamphetamine seeking (Moffett and Goeders, 2007).

Although our findings are consistent with results previously published with psychostimulants, they differ from the other findings which showed that treatment with the mixed CRF1/CRF2 antagonist D-Phe-CRF was not able to block cue-induced reinstatement to alcohol seeking (Liu and Weiss, 2002). The reason for this discrepancy could lie in the different chemical characteristics of the two antagonists antalarmin and D-Phe-CRF and to the related different permeability in the brain. D-Phe-CRF that is a peptidic compound was administered intracerebroventricularly while, in the present study, antalarmin has been administered systemically. Thus one possibility is that D-Phe-CRF was not sufficiently well distributed in brain areas involved in the control of the HPA axis. More importantly the two molecules differ in their specificity for the two CRF receptor subtypes. Antalarmin exhibits antagonist specific activity for CRF1 receptor whereas D-Phe-CRF exhibits antagonistic activity for both CRF1 and CRF2 receptors (Bakshi et al., 2007). While many studies have described a role for CRF1 receptor in alcohol-associated behaviors, less is known regarding the role of CRF2 receptor. Activation of CRF2 receptors decreases the anxiety associated with alcohol abstinence (Valdez et al., 2004) and its highly selective agonist urocortin 3 possesses anti-stress and anxiolytic properties (Valdez et al., 2003). Hence, it is possible that blockade of CRF2 may partly counteract the consequences of CRF1 inhibition. But, in conflict with this mechanism, it has also been shown that administration of CRF2 receptor antagonist produces anxiolytic-like effects (Takahashi et al., 2001) and that CRF2 knock-out mice exhibit an attenuation of morphine withdrawal symptoms (Papaleo et al., 2008). On the other hand, it has also been reported that the blockade of CRF2 receptor did not abate stress-induced reinstatement of cocaine seeking (Lu et al., 2001). It has been suggested that the presence of two CRF receptors with different effects could provide the CNS with more flexibility and dynamics in different conditions (Radulovic et al., 1999). In summary, while our results suggest an involvement of CRF1 receptor in cue-induced reinstatement of alcohol seeking with other evidences confirming this tendency for other drugs of abuse (Goeders and Clampitt, 2002; Moffett and Goeders, 2007), at present there is no similar evidence that link CRF2 receptor with cue-induced relapse.

In a previous study Goeders and Clampitt (2002), trained rats to self-administer cocaine in the presence of a specific set of environmental cues, following extinction rats were tested for relapse to cocaine seeking. Data showed that plasma corticosterone levels increased during cocaine self-administration, extinction and reinstatement (Goeders and Clampitt, 2002). Based on this finding we predicted the possibility that under our experimental condition administration of CORT could facilitate cue-induced reinstatement of alcohol seeking. To test this hypothesis we administered CORT prior to the reinstatement test. However, contrary to our prediction, its administration did not affect cue-induced reinstatement of alcohol seeking. This finding, challenge our previous observation with metyrapone and appears to contrast our hypothesis of an involvement of the HPA axis in cue-induced relapse. Nevertheless, it is important to note that, in a study with cocaine, the CORT dose-response curve induced by stress exposure had a bell-shaped form, which means that not the highest, but the middle dose of CORT in plasma was the most effective on reinstatement of cocaine seeking (Deroche et al., 1997). Therefore, it is possible that the exposure to environmental stimuli in the procedure used here was sufficient to increase CORT plasma levels to elicit the peak response, consequently reaching a ceiling effect, such that a further increase in plasma CORT levels (as a result of CORT administration) would not result in an observable response in the animals.

Moreover, in studies with cocaine and amphetamine it was demonstrated that CORT levels and its effect change with time during the presentation of environmental cues predictive of drug availability (Keller et al., 2013). Thus it is also possible that CORT effect on cue-induced reinstatement of alcohol seeking could be greatly influenced by the time of administration making hard to detect an effect of the hormone.

In summary, the results obtained here suggest the involvement of the CRF1 receptor in cue-induced relapse to alcohol seeking possibly through activation of the HPA axis. It is possible that drugs able to blunt HPA axis response could be beneficial for the treatment of relapse to alcohol seeking.

\section{Acknowledgements}

The authors would like to thank Rina Righi, Mariangela Fiorelli and Alfredo Fiorelli for technical support. This work was supported by National Institutes of Health grant RO1 AA017447 from the National Institute on Alcohol Abuse and Alcoholism.

\section{References}

Bachteler, D., Economidou, D., Danysz, W., Ciccocioppo, R., Spanagel, R., 2005. The effects of acamprosate and neramexane on cue-induced reinstatement of ethanol-seeking behavior in rat. Neuropsychopharmacology 30, 1104-1110.

Bakshi, V.P., Newman, S.M., Smith-Roe, S., Jochman, K.A., Kalin, N.H., 2007. Stimulation of lateral septum CRF2 receptors promotes anorexia and stress-like behaviors: functional homology to CRF1 receptors in basolateral amygdala. J. Neurosci. 27, 10568-10577.

Breese, G.R., Sinha, R., Heilig, M., 2011. Chronic alcohol neuroadaptation and stress contribute to susceptibility for alcohol craving and relapse. Pharmacol. Ther. 129, 149-171.

Brooks, S.P., Hennebry, G., Croft, A.P., Thomas, A., Little, H.J., 2004. Effects of corticosterone on place conditioning to ethanol. Psychopharmacology 174, 291-299.

Cannella, N., Economidou, D., Kallupi, M., Stopponi, S., Heilig, M., Massi, M., Ciccocioppo, R., 2009. Persistent increase of alcohol-seeking evoked by neuropeptide S: an effect mediated by the hypothalamic hypocretin system. Neuropsychopharmacology 34, 2125-2134. 
Ciccocioppo, R., Angeletti, S., Weiss, F., 2001. Long-lasting resistance to extinction of response reinstatement induced by ethanol-related stimuli: role of genetic ethanol preference. Alcohol. Clin. Exp. Res. 25, 1414-1419.

Ciccocioppo, R., Economidou, D., Fedeli, A., Angeletti, S., Weiss, F., Heilig, M., Massi M., 2004. Attenuation of ethanol self-administration and of conditioned reinstatement of alcohol-seeking behaviour by the antiopioid peptide nociceptin/ orphanin FQ in alcohol-preferring rats. Psychopharmacology 172, 170-178.

Ciccocioppo, R., Lin, D., Martin-Fardon, R., Weiss, F., 2003. Reinstatement of ethanol seeking behavior by drug cues following single versus multiple ethanol intoxication in the rat: effects of naltrexone. Psychopharmacology 168, 208-215.

Cippitelli, A., Damadzic, R., Singley, E., Thorsell, A., Ciccocioppo, R., Eskay, R.L., Heilig, M., 2012. Pharmacological blockade of corticotropin-releasing hormone receptor 1 (CRH1R) reduces voluntary consumption of high alcohol concentrations in non-dependent Wistar rats. Pharmacol. Biochem. Behav. 100 522-529.

Coover, G.D., Goldman, L., Levine, S., 1971. Plasma corticosterone increases produced by extinction of operant behavior in rats. Physiol. Behav. 6, 261-263.

Deroche, V., Marinelli, M., Le Moal, M., Piazza, P.V., 1997. Glucocorticoids and behavioral effects of psychostimulants. II: Cocaine intravenous self-administration and reinstatement depend on glucocorticoid levels. J. Pharmacol. Exp. Ther. 281, 1401-1407.

Deroche, V., Piazza, P.V., Le Moal, M., Simon, H., 1993. Individual differences in the psychomotor effects of morphine are predicted by reactivity to novelty and influenced by corticosterone secretion. Brain Res. 623, 341-344.

Fahlke, C., Engel, J.A., Eriksson, C.J., Hard, E., Soderpalm, B., 1994a. Involvement of corticosterone in the modulation of ethanol consumption in the rat. Alcohol 11, 195-202.

Fahlke, C., Hard, E., Eriksson, C.J., Engel, J.A., Hansen, S., 1995. Consequence of longterm exposure to corticosterone or dexamethasone on ethanol consumption in the adrenalectomized rat, and the effect of type I and type II corticosteroid receptor antagonists. Psychopharmacology 117, 216-224.

Fahlke, C., Hard, E., Thomasson, R., Engel, J.A., Hansen, S., 1994b. Metyrapone-induced suppression of corticosterone synthesis reduces ethanol consumption in high-preferring rats. Pharmacol. Biochem. Behav, 48, 977-981.

Goeders, N.E., Clampitt, D.M., 2002. Potential role for the hypothalamo-pituitaryadrenal axis in the conditioned reinforcer-induced reinstatement of extinguished cocaine seeking in rats. Psychopharmacology 161, 222-232.

Graf, E.N., Wheeler, R.A., Baker, D.A., Ebben, A.L., Hill, J.E., McReynolds, J.R., Robble, M.A., Vranjkovic, O., Wheeler, D.S., Mantsch, J.R., Gasser, P.J., 2013. Corticosterone acts in the nucleus accumbens to enhance dopamine signaling and potentiate reinstatement of cocaine seeking. J. Neurosci. 33, 11800-11810.

Heilig, M., Egli, M., Crabbe, J.C., Becker, H.C., 2010. Acute withdrawal, protracted abstinence and negative affect in alcoholism: are they linked? Addict. Biol. 15, 169-184.

Heilig, M., Koob, G.F., 2007. A key role for corticotropin-releasing factor in alcohol dependence. Trends Neurosci. 30, 399-406.

Kawasaki, K., Iwasaki, T., 1997. Corticosterone levels during extinction of runway response in rats. Life Sci. 61, 1721-1728.

Keller, C.M., Cornett, E.M., Guerin, G.F., Goeders, N.E., 2013. Combinations of oxazepam and metyrapone attenuate cocaine and methamphetamine cue reactivity. Drug Alcohol Depend. 133, 405-412.

Koob, G., Kreek, M.J., 2007. Stress, dysregulation of drug reward pathways, and the transition to drug dependence. Am. J. Psychiatry 164, 1149-1159.

Koob, G.F., 2003. Neuroadaptive mechanisms of addiction: studies on the extended amygdala. Eur. Neuropsychopharmacol. 13, 442-452.

Koob, G.F., 2010. The role of CRF and CRF-related peptides in the dark side of addiction. Brain Res. 1314, 3-14.

Koob, G.F., Ahmed, S.H., Boutrel, B., Chen, S.A., Kenny, P.J., Markou, A., O'Dell, L.E. Parsons, L.H., Sanna, P.P. 2004. Neurobiological mechanisms in the transition from drug use to drug dependence. Neurosci. Biobehav. Rev. 27, 739-749.

Koob, G.F., Zorrilla, E.P., 2010. Neurobiological mechanisms of addiction: focus on corticotropin-releasing factor. Curr. Opin. Investig. Drugs 11, 63-71.

Koob, G.F., Zorrilla, E.P., 2012. Update on corticotropin-releasing factor pharmacotherapy for psychiatric disorders: a revisionist view. Neuropsychopharmacology 37, 308-309.

Kreek, M.J., Koob, G.F., 1998. Drug dependence: stress and dysregulation of brain reward pathways. Drug Alcohol Depend. 51, 23-47.
Le, A.D., Harding, S., Juzytsch, W., Watchus, J., Shalev, U., Shaham, Y., 2000. The role of corticotrophin-releasing factor in stress-induced relapse to alcohol-seeking behavior in rats. Psychopharmacology 150, 317-324.

Liu, X., Weiss, F., 2002. Additive effect of stress and drug cues on reinstatement of ethanol seeking: exacerbation by history of dependence and role of concurrent activation of corticotropin-releasing factor and opioid mechanisms. J. Neurosci. 22, 7856-7861.

Logrip, M.L., Koob, G.F., Zorrilla, E.P., 2011. Role of corticotropin-releasing factor in drug addiction: potential for pharmacological intervention. CNS Drugs 25 , 271-287.

Lu, L., Liu, D., Ceng, X., 2001. Corticotropin-releasing factor receptor type 1 mediates stress-induced relapse to cocaine-conditioned place preference in rats. Eur. J. Pharmacol. 415, 203-208.

Marinelli, P.W., Funk, D., Juzytsch, W., Harding, S., Rice, K.C., Shaham, Y., Le, A.D., 2007. The CRF1 receptor antagonist antalarmin attenuates yohimbine-induced increases in operant alcohol self-administration and reinstatement of alcohol seeking in rats. Psychopharmacology 195, 345-355.

Moffett, M.C., Goeders, N.E., 2007. CP-154,526, a CRF type-1 receptor antagonist, attenuates the cue-and methamphetamine-induced reinstatement of extinguished methamphetamine-seeking behavior in rats. Psychopharmacology 190, 171-180.

Papaleo, F., Ghozland, S., Ingallinesi, M., Roberts, A.J., Koob, G.F., Contarino, A., 2008. Disruption of the $\mathrm{CRF}(2)$ receptor pathway decreases the somatic expression of opiate withdrawal. Neuropsychopharmacology 33, 2878-2887.

Piazza, P.V., Deroche, V., Deminiere, J.M., Maccari, S., Le Moal, M., Simon, H., 1993. Corticosterone in the range of stress-induced levels possesses reinforcing properties: implications for sensation-seeking behaviors. Proc. Natl. Acad. Sci. USA 90, 11738-11742.

Piazza, P.V., Marinelli, M., Jodogne, C., Deroche, V., Rouge-Pont, F., Maccari, S., Le Moal, M., Simon, H., 1994. Inhibition of corticosterone synthesis by Metyrapone decreases cocaine-induced locomotion and relapse of cocaine self-administration. Brain Res. 658, 259-264.

Radulovic, J., Ruhmann, A., Liepold, T., Spiess, J., 1999. Modulation of learning and anxiety by corticotropin-releasing factor (CRF) and stress: differential roles of CRF receptors 1 and 2. J. Neurosci. 19, 5016-5025.

Rivier, C., Imaki, T., Vale, W., 1990. Prolonged exposure to alcohol: effect on CRF mRNA levels, and CRF- and stress-induced ACTH secretion in the rat. Brain Res. $520,1-5$.

Smith, S.M., Vale, W.W., 2006. The role of the Hypothalamic-Pituitary-Adrenal axis in neuroendocrine responses to stress. Dialog. Clin. Neurosci. 8, 383-395.

Stopponi, S., Somaini, L., Cippitelli, A., Cannella, N., Braconi, S., Kallupi, M., Ruggeri, B., Heilig, M., Demopulos, G., Gaitanaris, G., Massi, M., Ciccocioppo, R., 2011. Activation of nuclear PPARgamma receptors by the antidiabetic agent pioglitazone suppresses alcohol drinking and relapse to alcohol seeking. Biol. Psychiatry 69, 642-649.

Takahashi, L.K., Ho, S.P., Livanov, V., Graciani, N., Arneric, S.P., 2001. Antagonism of CRF(2) receptors produces anxiolytic behavior in animal models of anxiety. Brain Res. 902, 135-142.

Valdez, G.R., Sabino, V., Koob, G.F., 2004. Increased anxiety-like behavior and ethanol self-administration in dependent rats: reversal via corticotropin-releasing factor-2 receptor activation. Alcohol. Clin. Exp. Res. 28, 865-872.

Valdez, G.R., Zorrilla, E.P., Rivier, J., Vale, W.W., Koob, G.F., 2003. Locomotor suppressive and anxiolytic-like effects of urocortin 3, a highly selective type 2 corticotropin-releasing factor agonist. Brain Res. 980, 206-212.

Vale, W., Spiess, J., Rivier, C. Rivier, J., 1981. Characterization of a 41-residue ovine hypothalamic peptide that stimulates secretion of corticotropin and beta-endorphin. Science 213, 1394-1397.

Van Pett, K., Viau, V., Bittencourt, J.C., Chan, R.K., Li, H.Y., Arias, C., Prins, G.S., Perrin, M., Vale, W., Sawchenko, P.E., 2000. Distribution of mRNAs encoding CRF receptors in brain and pituitary of rat and mouse. J. Comp. Neurol. 428, 191-212.

Vengeliene, V., Heidbreder, C.A., Spanagel, R., 2007. The effects of lamotrigine on alcohol seeking and relapse. Neuropharmacology 53, 951-957.

Zorrilla, E.P., Koob, G.F., 2004. The therapeutic potential of CRF1 antagonists for anxiety. Expert Opin. Investig. Drugs 13, 799-828.

Zorrilla, E.P., Valdez, G.R., Weiss, F., 2001. Changes in levels of regional CRF-likeimmunoreactivity and plasma corticosterone during protracted drug withdrawal in dependent rats. Psychopharmacology 158, 374-381. 